\title{
Uncommon complications of ventriculoperitoneal shunt surgery: review of four cases and literature review
}

\author{
Aliyu Muhammad Koko ${ }^{1 *}$, Nasiru Jinjiri Ismail ${ }^{1}$, Ali Lasseini ${ }^{1}$ and Sahabi M. Saddiku²
}

\begin{abstract}
Background: Ventriculoperitoneal shunt is one of the most popular cerebrospinal fluid diversion procedures worldwide. Complications are common, but uncommon complications are rarely reported in the literature making a standardized guideline on management of unusual complications unavailable. We report this series of uncommon complications managed in our centre to share our experience and contribute to the pool of literature on the management of these weird complications of ventriculoperitoneal shunting.

Case presentation: The first case was a 10-year-old girl who presented with headache, early morning vomiting and itching over the tract of the shunt in the neck. She has had ventriculoperitoneal shunt and excision and repair of encephalocele at the age of 3 months in our facility. On physical examination, she was conscious with a Glasgow coma score of 15, and shunt valve was hardened. She had removal of the shunt with intraoperative finding of calcified shunt tubing and the valve, and also cerebrospinal fluid was under high pressure that warranted re-insertion of another medium pressure shunt. She remained stable at last follow-up 3 months post-surgery. We managed two cases of shunt extrusion via the anus (a 1-year-old female infant and 9-year-old boy). None of the patients presented with evidence of peritonitis or shunt tract infection. The extruded shunts were removed under aseptic technique, and both patients had ventriculoperitoneal shunt re-inserted because of progression of hydrocephalus. They remained stable at last follow-up visits 6 months after surgery.

The fourth case was a 9-month-old infant that presented with shunt extrusion via the abdominal wound site 3 weeks after ventriculoperitoneal shunt procedure. The child developed an abscess at the abdominal wound that ruptures spontaneously with extrusion of distal catheter, had no features of peritonitis and had shunt removed and re-inserted after 3 months. The child has remained stable.

Conclusion: Although ventriculoperitoneal shunt calcification and extrusion are rare, they do occur. None of our patients had peritonitis. Shunt removal and subsequent reinsertion in the presence of raised intracranial pressure from hydrocephalus confirms an excellent outcome.
\end{abstract}

Keywords: Ventriculoperitoneal shunt, Calcification, Anal extrusion, Uncommon complications

\section{Introduction}

Ventriculoperitoneal shunt (VP) is one of the commonly performed neurosurgical procedures for the treatment of hydrocephalus [1]. A wide range of complications can occur along the path of the shunt from the ventricle to the peritoneal cavity $[1,2]$. The complications of ventriculoperitoneal shunting may lead to failure of the

\footnotetext{
* Correspondence: kokoaliyu1@gmail.com

${ }^{1}$ Department of Neurosurgery, Regional Centre for Neurosurgery, Usmanu

Danfodiyo University Teaching Hospital Sokoto, Sokoto, Nigeria

Full list of author information is available at the end of the article
}

procedure necessitating revision or reinsertion in most of the affected patients.

Calcification of ventriculoperitoneal shunt and associated dysfunction are unusual events in neurosurgery; the incidence of this weird complication is unknown, and few cases have been reported in the literature. Variable pathophysiological mechanisms of shunt calcification have been reported, and some authors implicated deranged calcium and phosphate metabolism and renal failure while others documented that shunt calcification could occur in the presence normal calcium and 
phosphate level and attributed to dystrophic calcification, altered cellular metabolism and quality of the shunt catheter used [3]. Calcification usually occurs as a longterm complication of shunt procedure and may be followed by shunt rupture, dysfunction and consequent increase in intracranial pressure [3-6] (Table 1).

The incidence rates of ventriculoperitoneal shunt complication range from 24 to $47 \%$, and $25 \%$ of these are abdominal [7]. The incidence of intestinal perforation is reported at 0.1 to $0.7 \%$. Shunt migration has been reported to occur in various parts of the body including but not limited to the abdominal wall, gastrointestinal tract, vagina, bladder, scrotum, mediastinum and oral cavity. Bowel perforation and anal protrusion of the lower end of the peritoneal catheter is uncommon; the mechanism of bowel perforation may be due to pressure by a hard-tipped peritoneal end in addition to continuous cerebrospinal fluid pulse pressure on weak intestinal musculature in children and chronic irritative process of the distal catheter [7]. Intestinal perforation is usually asymptomatic but can be complicated by shunt tract infection and peritonitis with attendant morbidity and mortality $[8,9]$. This paper aimed to report four uncommon complications of ventriculoperitoneal shunting and outline the management.

\section{Case description}

\section{Case one}

A 10-year-old female patient presented with headache, early morning vomiting, itching and burning sensation over the shunt tract in the retroauricular area that begins 2 months prior to presentation. The patient had ventriculoperitoneal shunt (medium pressure Chhabra shunt) on the right side, excision and repair of occipital encephalocele when she was 3 months old. On examination, her Glasgow coma score was 15 and had no neurological deficits. There was firm, thickened soft tissues around the shunt tract, spanning the retroauricular area and upper part of the neck. The shunt tube was stuck to the surrounding tissues with some degree of tethering. Intraoperatively, the shunt was found to be stuck to the subcutaneous tissue with calcified fibrous adhesions along the shunt tubing, but the ventricular catheter was removed with ease with no evidence of trapping by the choroid plexus (Fig. 1). A new shunt was inserted on the right side via a de novo tract. Histopathological study confirmed the calcification of tissues around the shunt (Fig. 2). The patient was discharged in satisfactory condition after 7 days of treatment, and she is currently doing well.

\section{Case two}

The second case was a 1-year-old female child who presented with extrusion of ventriculoperitoneal shunt

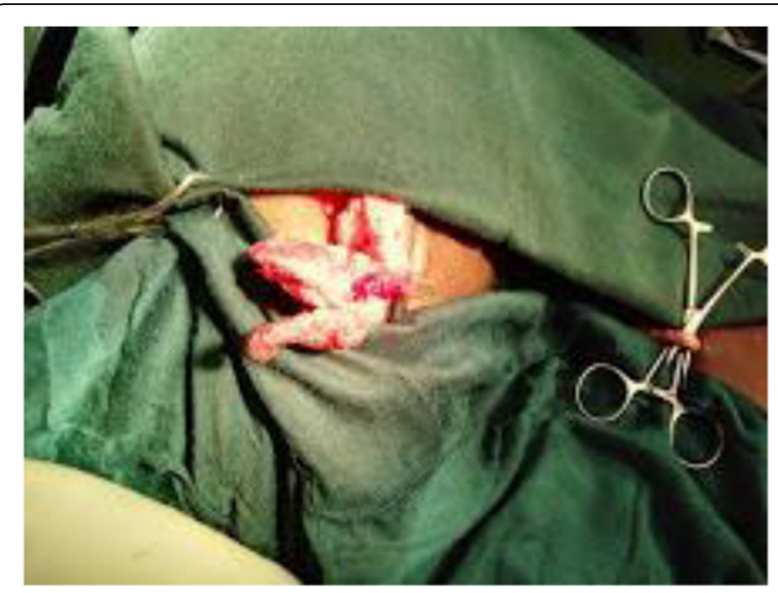

Fig. 1 Calcified tissue

catheter through the anus (Fig. 3). The child had VP, shunt, excision and repair of myelomeningocele and manual reduction of prolapsed rectum at the age of 3 months. There was a history of VP shunt revision on account of distal obstruction 4 months after the initial shunt surgery.

The child was stable, with no features of meningitis or peritonitis. The patient was taken to the operating room, and previous abdominal incision was opened; the shunt catheter was cut and gently pulled out by the extruded anal portion. The rest of the shunt tubing was removed by an incision at the head end. The patient had antibiotics coverage and acetazolamide, and VP shunt was reinserted 6 weeks later due to features of tensed hydrocephalus. The patient was well at last follow-up 4 months after shunt placement.

\section{Case three}

The third case was a nine-year-old boy who presented with extrusion of ventriculoperitoneal shunt catheter

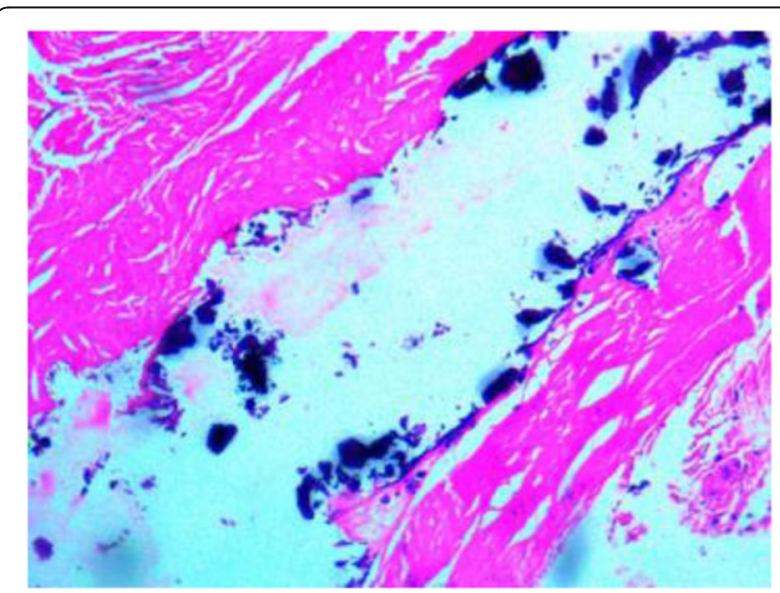

Fig. 2 Photomicrograph showing calcified tract 


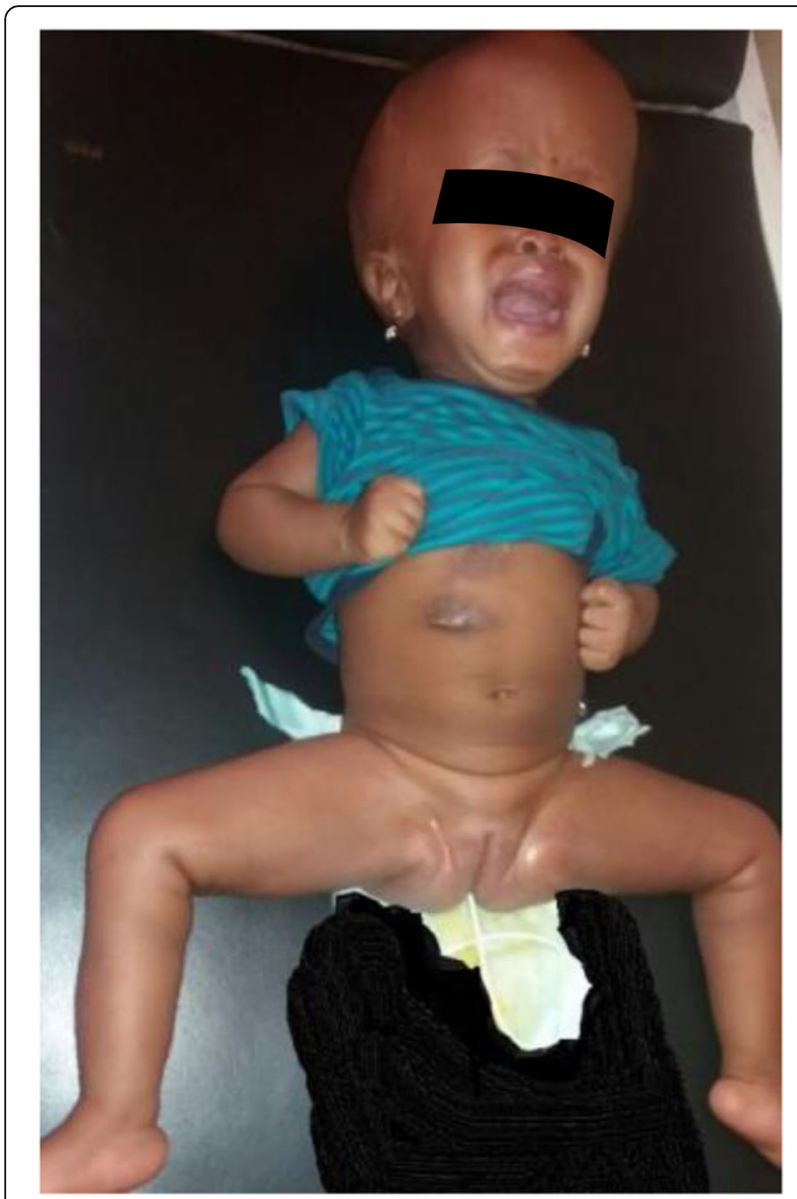

Fig. $3 \mathrm{~A}$ female infant with shunt extrusion through the anus

through the anus (Fig. 4). The boy had ventriculoperitoneal shunt for post-meningitic hydrocephalus when he was 1 year old.

The patient was stable, with no features of meningitis or peritonitis. The patient was taken to the operating room, and the shunt catheter was removed the same way as the second patient above. The patient had antibiotics coverage, and repeat brain computerized tomographic scan

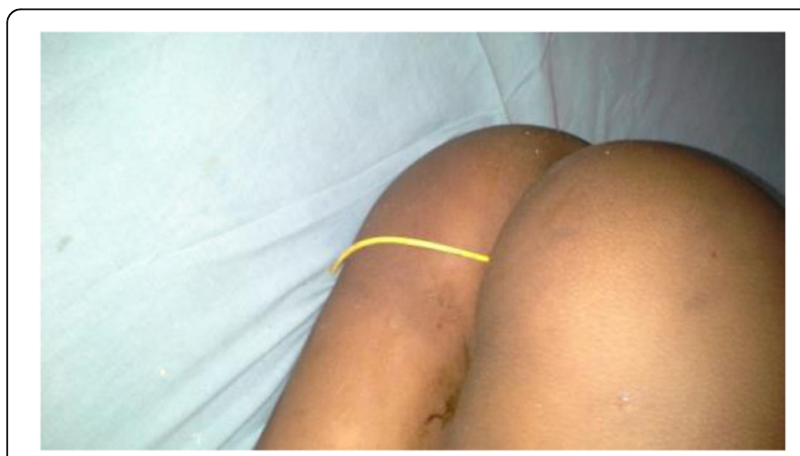

Fig. 4 Showing shunt extrusion via anus showed ventricular dilatation. He was initially placed on acetazolamide, and ventriculoperitoneal shunt was reinserted 6 weeks later due to features of raised intracranial pressure. The patient was well at last follow-up 6 months after shunt placement.

\section{Case four}

The fourth case was a 9 months old infant with distal catheter extrusion via a previous abdominal incision site 6 months after VP shunt (Fig. 5). There were no features of infection. The shunt was removed and subsequent repeat shunt was done on the right side cranially but tunneled to the left paraumbilical area to avoid possible bowel adhesions on the extruded side 3 months later. The patient is currently stable.

\section{Discussion}

Ventriculoperitoneal shunt is one of the most accepted cerebrospinal fluid diversion procedures for the management of hydrocephalus [1] (Tables 1 and 2). However, the procedure is associated with numerous complications, which can occur in the early postoperative period or years after shunting [1].

Shunt calcification has been recognized as one of the rare late complications of ventriculoperitoneal shunt surgery; few cases were reported in the literature [3] (Table 1). The first case of shunt calcification was reported in 1988 [10]. The deposition of calcium and other minerals on the shunt catheter may cause dysfunction, by disconnection of tubing or obstruction due to tethering of shunt tube

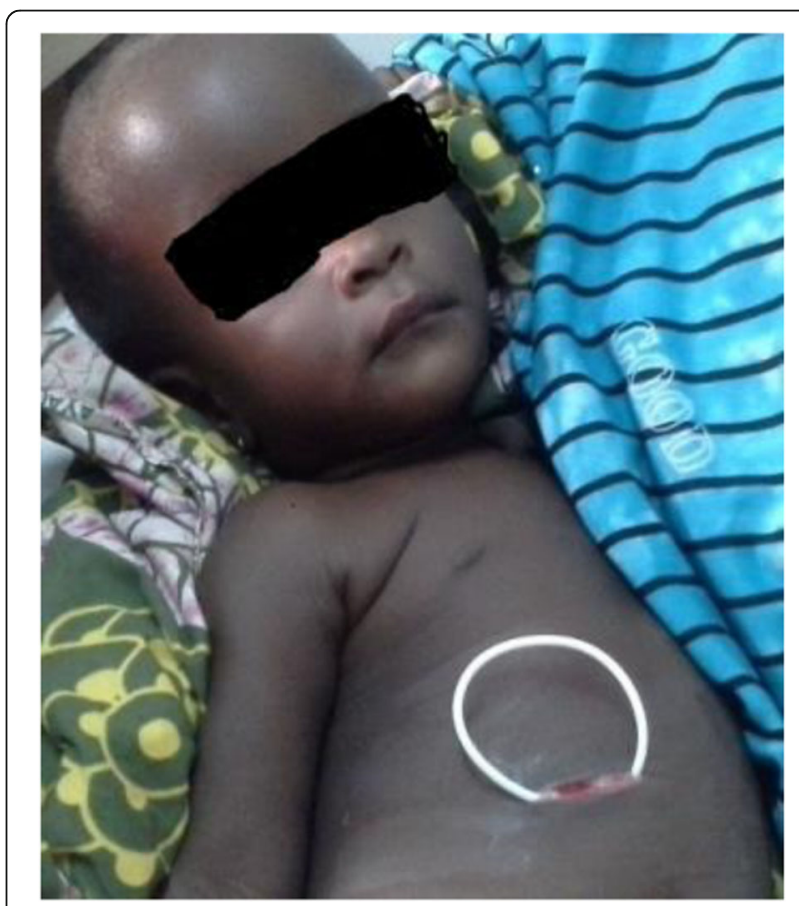

Fig. 5 Showing shunt extrusion via previous abdominal incision 
Table 1 Summary of cases with calcified ventriculoperitoneal shunts

\begin{tabular}{|c|c|c|c|c|c|}
\hline SN & Author and yr & Number of case(s) & Age, years/sex & Treatment & Outcome \\
\hline 1 & Sakai et al. (2004) [6] & 1 & $53 / \mathrm{M}$ & Shunt removal and re-insertion of a new one & Survived \\
\hline 2 & Cakir et al. (2004) [5] & 1 & $16 / F$ & Shunt removal and re-insertion of a new one & Survived \\
\hline 3 & Abubakar et al. (2015) [3] & 2 & $\begin{array}{l}17 / \mathrm{M} \\
17 / \mathrm{F}\end{array}$ & Shunt removal and re-insertion of a new one & Survived \\
\hline 4 & Kural et al. (2012) [11] & 1 & 10/M & Shunt removal and re-insertion of a new one & Survived \\
\hline
\end{tabular}

Yr year of publication, $S N$ serial number

[3]. In our patient, the catheter was tethered to the calcified fibrous tissue thereby causing dysfunction of the shunt catheter system. The youth of the patients at the time of initial shunt insertion and the length of time the shunt stay in the patients were considered the most significant factors in shunt calcification [11]. In our index case, the patient was an infant when the shunt was inserted and it was in the patient for almost 10 years. It is of note that the clinical features of hydrocephalus in our patient started 2 months prior to presentation. We believed that the shunt tethering and dysfunction may have occurred many months ago, but the compensatory mechanisms of the brain delayed the onset of clinical symptoms of hydrocephalus in our patient (Tables 1 and 2).

Management of shunt calcification depends on the extent of calcification, functionality of the shunt catheter and presence of raised intracranial pressure. In the presence of proximal catheter trapping by the choroid plexus or calcified intracranial tissue, it is wise not to pull the ventricular catheter with force so as to avoid the dreadful complication of intracranial haemorrhage; simple removal of the distal catheter and reinsertion of new shunt should suffice. As in our index case, there was no trapping of the ventricular catheter, shunt tubing was removed and a new one replaced via a de novo tract. It is not unexpected that calcified shunt can be removed without the need for shunt replacement in the absence of elevated intracranial pressure or neurological manifestations attributable to active hydrocephalus.

Bowel perforation and anal extrusion of peritoneal shunt catheter is an unusual phenomenon which was first reported in the literature by Wilson and Bertrand in 1966 [12].

The exact mechanism of ventriculoperitoneal shuntrelated bowel perforation is not clear. However, it has been hypothesized that the adherence of the catheter tip to the visceral wall and constant pressure of the catheter tip along with local inflammatory reaction lead to perforation of the wall of viscera and entrance of tip in the lumen $[1,13]$. The peristaltic activity of the bowel carries it all the way to anus and the external surface [13]. Other pathogenetic mechanisms include poor general condition of the patients, with weakening of the bowel wall and the firm end of the peritoneal catheter leading to perforation of the intestine [13]. Children as the index cases are more prone to shunt-related bowel perforation because of the weak bowel musculature [13]. The options of treatment of shunt extrusion can be determined by the presence of infection as well as active hydrocephalus. Simple removal of shunt catheter, microbiological study of the shunt tubing and antibiotics therapy would suffice. Subsequent re-insertion of shunt in the presence of active hydrocephalus may be done between 6 and 12 weeks; this is to allow the infection to be treated and inflammation to settle and heal before another ventriculoperitoneal shunting. Patients are usually placed on medical management using acetazolamide before a new shunt is inserted to minimize the effects of raised intracranial pressure. Though conversion of extruded shunt to an external ventricular drain may be more effective in reducing the elevated intracranial pressure, it is more tasking, would need to be repeated on several occasions before infection and inflammation are controlled and is really costly in developing countries where most patients are poor and have to settle hospital bills from their pocket. We have used a medium pressure Chhabra shunt for all our patients, which have a soft peritoneal end. The use of soft silicone-made shunt is encouraged, as it may excite less foreign body reaction and decrease the rate of complications [1].

Table 2 Summary of cases with anal extrusion of ventriculoperitoneal shunt

\begin{tabular}{|c|c|c|c|c|c|}
\hline SN & Author(s)/yr & Age at VPS & Time from placement to diagnosis & Management & Outcome \\
\hline 1 & Grosfeld et al. (1974) [14] & 2 & 10 months & Shunt removed & Recovery \\
\hline 2 & Sarkari et al. (2016) [1] & 2 & 6 months & Shunt removed & Recovery \\
\hline 3 & Sathyanarayana et al. (2000) [9] & 42 & 6 months & Shunt removed & Recovery \\
\hline 4 & Sreedhar et al. (2009) [7] & 6 & 4 months & Shunt removed & Recovery \\
\hline
\end{tabular}

VPS ventriculoperitoneal shunt, $Y r$ year of publication, $S N$ serial number 


\section{Conclusion}

Ventriculoperitoneal shunts might be complicated rarely, by calcification or bowel perforation and anal extrusion. Clinicians should keep abreast of these unusual complications. Close follow-up and aggressive management are advised, so as to reduce morbidity and mortality.

\section{Abbreviations}

Fig.: Figure; VP: Ventriculoperitoneal shunt

\section{Acknowledgements}

We thank all the staff of the Department of Neurosurgery for their commitment in managing our patients.

\section{Authors' contributions}

AMK contributed to the conception of the research, preparation of clinical details and literature review. $\mathrm{NJ}$ contributed to the conception of the research, preparation of clinical details and literature review. AL contributed to the conception of the research, preparation of clinical details and literature review. SMS contributed to the conception of the research, preparation of clinical details and literature review. All authors read and approved the final manuscript.

\section{Funding}

None

\section{Availability of data and materials}

The data can be found from case files of the patients at the medical record section of the Department of Neurosurgery and surgical images archive of the Department of Neurosurgery.

Ethics approval and consent to participate

Not applicable.

\section{Consent for publication}

Consent to publish has been obtained from the parents of the patients involved.

\section{Competing interests}

The authors declare that they have no competing interests.

\section{Author details}

'Department of Neurosurgery, Regional Centre for Neurosurgery, Usmanu Danfodiyo University Teaching Hospital Sokoto, Sokoto, Nigeria. ${ }^{2}$ Department of Histopathology, Usmanu Danfodiyo University Teaching Hospital Sokoto, Sokoto, Nigeria.

Received: 26 July 2019 Accepted: 13 December 2019

Published online: 09 January 2020

\section{References}

1. Sarkari A, Borkar SA, Mahapatra AK. Anal extrusion of migrated ventriculoperitoneal shunt catheter: an unusual complication and review of literature. Asian J Neurosurg. 2016:11:459.

2. Bryant MS, Bremer AM. Abdominal complications of ventriculo-peritoneal shunts. Case report and review of literature. Am Surg. 1988:54:50-5.

3. Abubakar DS, Mohammed AE, Haddab AM, Baha EM. Shunt tube calcification as a late complication of ventriculoperitoneal shunting. Asian J Neurosurg. 2015;1093:246-9.

4. Boch AL, Hermelin E, Sainte-Rose C, Sgouros S. Mechanical dysfunction of ventriculoperitoneal shunts caused by calcification of the silicone rubber catheter. J Neurosurg. 1998:88:975-82

5. Cakir E, Kuzeyli K, Usul H, Peksoylu B, Kararslan G, Yildiz K. Shunt dysfunction due to calcification of a ventriculoperitoneal shunt: a case report. J Clin Neurosci. 2004:11:210-1.

6. Sakai S, Akai T, Lida T, Lizuka H. Calcification on the ventricle wall associated with a shunt tube-case report. Neurol Med Chir (Tokyo). 2004:44:674-6.

7. Sreedhar V, Sreenivas RR, Vamsidhar RT, Manas KP. Anal extrusion of ventriculoperitoneal shunt tube: endoscopic removal. J Paediatr Neurosci. $2009 ; 4(2): 124-6$
8. Odebode TO. Jejunal perforation and peroral extrusion of a peritoneal shunt catheter. Br J Neurosurg. 2007;21:235-6.

9. Sathyanarayana S, Wylen EL, Baskaya MK, Nanda A, Bando Y, Manabe Y, et al. Spontaneous bowel perforation after ventriculoperitoneal shunt surgery: case report and a review of 45 cases. Surg Neurol. 2000;54:388-96.

10. Shimotake K, Kondo A, Aoyama I, Nin K, Tashiro Y, Nishioka T. Calcification of a ventriculoperitoneal shunt tube. Case report Surg Neurol. 1988;30:156-8.

11. Cahit K, Alparslan K, Serhat P, Tolga S, Yusuf I. Late calcification and rupture; a rare complication of ventriculoperitoneal shunting. Turkish Neurosurg. 2012;22(6):779-82

12. Wilson $\mathrm{CB}$, Bertrand $\mathrm{V}$. Perforation of bowel complicating peritoneal shunt for hydrocephalus. Report of two cases Am Surg. 1966;32:601-3.

13. Akyuz M, Ucar T, Goksu E. A thoracic complication of ventriculoperitoneal shunt: symptomatic hydrothorax from intrathoracic migration of a ventriculo-peritoneal shunt catheter. Br J Neurosurg. 2004;18:171-3.

14. Grosfeld JL, Cooney DR, Smith J, Campbell RL. Intraabdominal complications following ventriculoperitoneal shunt procedures. Pediatrics. 1974;54:791-6.

\section{Publisher's Note}

Springer Nature remains neutral with regard to jurisdictional claims in published maps and institutional affiliations.

\section{Submit your manuscript to a SpringerOpen ${ }^{\circ}$ journal and benefit from:}

- Convenient online submission

- Rigorous peer review

- Open access: articles freely available online

- High visibility within the field

- Retaining the copyright to your article

Submit your next manuscript at $\boldsymbol{\nabla}$ springeropen.com 